\title{
Publicidad y leyes de violencia de género. Estudio empírico en España y Argentina
}

Marta Martín Llaguno¹ I marta.martin@ua.es

Marián Navarro Beltrá² I marian.navarro@ua.es

UNIVERSIDAD DE ALICANTE

Resumen: Recientemente en España y en Argentina se han promulgado normas para erradicar la violencia machista que, entre otras cuestiones, penalizan el uso de determinados estereotipos en la publicidad. Con el objetivo de observar las consecuencias de este desarrollo normativo, una muestra representativa de spots es revisada a través de dichas consideraciones legales y del concepto sesgo de género. Los resultados muestran que la difícil operacionalización de los estereotipos de género capaces de suscitar violencia de género hace complejo evaluar el sexismo publicitario y, por tanto, su legalidad. No obstante, la cuantificación de los sesgos resulta útil para valorar este sexismo.

Palabras clave: género, publicidad, sexismo, violencia de género

Abstract: Spain and Argentina have recently enacted legislation to eradicate domestic violence. Among other things, these laws criminalize the use of certain stereotypes in advertising. In order to observe the consequences of this policy development, this paper reviews a representative sample of spots through such legal considerations and of concept gender bias. The results show that the vagueness of the difficulty in the operationalization of gender stereotypes can prompt gender violence makes complex to evaluate advertising sexism and, however, their legality. By contrast, the quantification of bias is useful to assess this sexism.

Key words: gender, advertising, sexism, gender violence

\footnotetext{
${ }^{1}$ Doctora en Ciencias de la Información por la Universidad de Navarra. Se incorpora a la Universidad de Alicante en 1997. Actualmente es Profesora Titular de Universidad de Deontología Publicitaria y Fundamentos de la Comunicación II del Área de Comunicación Audiovisual y Publicidad de la Universidad de Alicante.

2 Licenciada en Publicidad y Relaciones Públicas por la Universidad de Alicante con la obtención del Premio Extraordinario de Licenciatura. Obtención de la Suficiencia Investigadora en 2009. Actualmente es becaria FPI de la Generalitat Valenciana en el Departamento de Comunicación y Psicología Social de la Universidad de Alicante.
} 


\section{Las leyes para prevenir la violencia de género y la publicidad}

En las sociedades desarrolladas la desigualdad de género, y concretamente la violencia machista, se erigen como un tema de preocupación pública, por ello, se han impulsan políticas que tratan de corregir dicho problema.

En el año 1980, tal y como afirman Díaz-Aguado y Martínez, en la II Conferencia Mundial sobre la Mujer, realizada en Copenhague, es cuando se adopta, por vez primera, "una resolución sobre violencia. Concretamente se declaró que la violencia [machista] era un crimen contra la humanidad" (Vives, 2004: 40). A partir de los años 90, la erradicación de esta cuestión ha acaparado la atención pública.

En efecto, los desarrollos legales han abarcado distintos ámbitos de forma que, en algunas ocasiones, como muestra la tabla 1 , los medios de comunicación se han considerado herramientas fundamentales para prevenir las agresiones contra las mujeres.

Tabla 1: Medios de comunicación en las leyes contra la violencia machista

\begin{tabular}{|l|l|l|l|}
\hline País & Ley & Fecha & Medios \\
\hline Bolivia & $\begin{array}{l}\text { Ley 1674 Contra la } \\
\text { Violencia en la Familia } \\
\text { o Doméstica }\end{array}$ & $15-12-1995$ & $\begin{array}{l}\text { Considera importantes el } \\
\text { discurso y el lenguaje de los } \\
\text { medios para prevenir la } \\
\text { violencia en la familia }\end{array}$ \\
\hline Costa Rica & $\begin{array}{l}\text { Ley 7586 Contra la } \\
\text { Violencia Doméstica }\end{array}$ & $10-04-1996$ & $\begin{array}{l}\text { Estimula a los medios para que } \\
\text { formulen directrices para la } \\
\text { adecuada difusión de } \\
\text { información que contribuya a } \\
\text { erradicar la violencia } \\
\text { doméstica }\end{array}$ \\
& $\begin{array}{l}\text { Ley 8688 de Creación } \\
\text { del Sistema Nacional } \\
\text { Para la Atención y } \\
\text { Prevención de la } \\
\text { Violencia Contra las } \\
\text { Mujeres y la Violencia } \\
\text { Intrafamiliar }\end{array}$ & 04-12-2008 & $\begin{array}{l}\text { Entre las funciones de este } \\
\text { Sistema se encuentra } \\
\text { fomentar un uso apropiado de } \\
\text { los medios de comunicación } \\
\text { que ayude a eliminar la } \\
\text { violencia intrafamiliar y la } \\
\text { violencia contra las mujeres }\end{array}$ \\
\hline $\begin{array}{l}\text { Ley para Prevenir, } \\
\text { Sancionar y Erradicar } \\
\text { la Violencia } \\
\text { Intrafamiliar (Decreto } \\
\text { G7-1996) }\end{array}$ & 24-10-1996 & $\begin{array}{l}\text { Anima a los medios para que } \\
\text { formulen directrices adecuadas } \\
\text { de difusión que contribuyan a } \\
\text { erradicar la violencia } \\
\text { intrafamiliar }\end{array}$ \\
\hline Filipinas & $\begin{array}{l}\text { Anti-Violence Against } \\
\text { Women and Their } \\
\text { Children }\end{array}$ & $\begin{array}{l}\text { Alenta a los medios a } \\
\text { promover mensajes no } \\
\text { esteriotipados y sexistas que } \\
\text { perpetúen la violencia }\end{array}$ \\
\hline España & $\begin{array}{l}\text { Ley Orgánica 1/2004 } \\
\text { de Medidas de } \\
\text { Protección Integral } \\
\text { Contra la Violencia de } \\
\text { Género }\end{array}$ & 28-12-2004 & $\begin{array}{l}\text { Establece directrices para el } \\
\text { control de la publicidad ilícita }\end{array}$ \\
\hline
\end{tabular}




\begin{tabular}{|c|c|c|c|}
\hline Chile & $\begin{array}{l}\text { Ley } 20066 \text { de Violencia } \\
\text { Intrafamiliar }\end{array}$ & 22-09-2005 & $\begin{array}{l}\text { El Servicio Nacional de la } \\
\text { Mujer debe formular planes } \\
\text { que promuevan la cooperación } \\
\text { de los medios para eliminar la } \\
\text { violencia contra la mujer y } \\
\text { ensalzar el respeto a su } \\
\text { dignidad }\end{array}$ \\
\hline Brasil & $\begin{array}{l}\text { Ley } 11340 \text { de } \\
\text { Mecanismos Para } \\
\text { Frenar la Violencia } \\
\text { Domestica y Familiar } \\
\text { Contra la Mujer }\end{array}$ & 07-08-2006 & $\begin{array}{l}\text { Los medios deben respetar los } \\
\text { valores sociales y éticos de la } \\
\text { familia y del individuo para } \\
\text { frenar los estereotipos que } \\
\text { legitiman la violencia } \\
\text { doméstica }\end{array}$ \\
\hline Venezuela & $\begin{array}{l}\text { Ley Orgánica Sobre el } \\
\text { Derecho de las Mujeres } \\
\text { a una Vida Libre de la } \\
\text { Violencia }\end{array}$ & $25-11-2006$ & $\begin{array}{l}\text { Define la violencia mediática. } \\
\text { Los medios deben mostrar } \\
\text { mensajes promoviendo la } \\
\text { igualdad entre sexos y en } \\
\text { contra la violencia machista }\end{array}$ \\
\hline México & $\begin{array}{l}\text { Ley General de Acceso } \\
\text { de las Mujeres a una } \\
\text { Vida Libre de Violencia }\end{array}$ & $31-01-2007$ & $\begin{array}{l}\text { Medidas de vigilancia para que } \\
\text { los medios no promuevan } \\
\text { imágenes esteriotipadas de } \\
\text { mujeres y hombres }\end{array}$ \\
\hline Argentina & $\begin{array}{l}\text { Ley } 26.485 \text { de } \\
\text { Protección Integral } \\
\text { Para Prevenir, } \\
\text { Sancionar y Erradicar } \\
\text { la Violencia Contra las } \\
\text { Mujeres }\end{array}$ & 01-04-2009 & $\begin{array}{l}\text { Los medios pueden ejercer } \\
\text { agresión contra las mujeres al } \\
\text { considerar como una } \\
\text { modalidad de violencia de } \\
\text { género a la violencia } \\
\text { mediática. }\end{array}$ \\
\hline
\end{tabular}

Fuente: elaboración propia a partir de Vives-Cases, Ortíz-Barreda y Gil-González (2010: 474-475) y de http://www.uv.es/ dones/violen/LEYINTEGRAL.htm (consultado: 24/05/2011).

Las investigaciones científicas ponen de manifiesto la relación existente entre la violencia mostrada en los medios de comunicación y la violencia real, ya que hay más de 3.500 estudios que vinculan la violencia mediática con la agresividad desarrollada por niños y adolescentes (Strasburger, 2004: 57).

En este sentido, se ha especulado también con que la exposición repetida a imágenes que muestran estereotipos de género puede contribuir a aumentar la violencia contra la mujer (Lavine, Sweeney y Wagner, 1999: 1049).

En este escenario, la sociedad solicita a los discursos mediáticos un papel destacado en la erradicación del problema, bajo el supuesto de "educar para prevenir" (Sánchez, 2008: 155). Por una parte, se considera que si los medios son utilizados para repudiar las acciones violentas contra las mujeres, "su influencia dejará huella" en los potenciales maltratadores (2008: 157).

Así, si bien es cierto que los medios pueden presentar estereotipos distorsionadores de la realidad capaces de generar prejuicios (Loscertales y Núñez, 2009: 461), también lo es que pueden contribuir a la modificación de estos (Rodríguez, Matud y Espinosa, 2008: 576).

En este contexto, y pese a que la literatura sobre la incidencia de la publicidad sexista y la violencia de género es inexistente, especialmente en las leyes integrales (entre las cuales la 
española es pionera y la argentina más reciente) violencia de género y discursos publicitarios se han visto sistemáticamente asociados.

\subsection{El sexismo publicitario en las leyes española y argentina}

La Ley Orgánica de Medidas de Protección Integral contra la Violencia de Género española es, según Blanco (2009), "la primera ley en el mundo que, con carácter normativo, aborda de manera conjunta el problema de la violencia de género y de la discriminación" y que lo hace "desde el convencimiento de que la publicidad sexista puede generar violencia" (2009).

La repercusión más importante sobre los medios que tiene la entrada en vigor de esta ley pionera es la modificación inmediata de la Ley General de Publicidad, con la introducción de los dos supuestos básicos de publicidad ilícita relacionados con el género:

1. La presentación vejatoria de la mujer mediante el uso particular y directo de su cuerpo, o partes del mismo, como objeto desvinculado del producto promocionado;

2. La utilización de la imagen de la mujer "asociada a comportamientos estereotipados que vulneren los fundamentos de nuestro ordenamiento coadyuvando a generar" violencia de género.

Por su parte, la Ley de Protección Integral para Prevenir, Sancionar y Erradicar la Violencia contra las Mujeres de Argentina, benjamina entre las leyes integrales por ser la última promulgada, emula a la ley española, y corresponsabiliza a la comunicación social al considerar la violencia mediática como una modalidad de violencia contra las mujeres.

Así es ilícita toda

publicación o difusión de mensajes e imágenes estereotipados a través de cualquier medio masivo de comunicación, que de manera directa o indirecta promueva la explotación de mujeres o sus imágenes, injurie, difame, discrimine, deshonre, humille o atente contra la dignidad de las mujeres, como así también la utilización de mujeres, adolescentes y niñas en mensajes e imágenes pornográficas, legitimando la desigualdad de trato o construya patrones socioculturales reproductores de la desigualdad o generadores de violencia contra las mujeres.

Además la norma define la "violencia simbólica", que se produce cuando "a través de patrones estereotipados, mensajes, valores, íconos o signos transmita y reproduzca dominación, desigualdad y discriminación en las relaciones sociales, naturalizando la subordinación de la mujer en la sociedad".

Ambas normativas suscitan la crítica por varias razones:

- En primer lugar, por restringir el concepto de publicidad sexista y eliminar a los varones como posibles sujetos de este tipo de publicidad. De esta forma, Rodríguez 
(2008: 179) considera que la violencia machista es social y jurídicamente un concepto "que contempla todos aquellos delitos que se cometen contra la mujer".

- En segundo lugar, y sobre todo, por no concretar suficientemente lo qué entiende el legislador por "comportamientos/patrones estereotipados" y por lo que implica coadyuven a generar violencia de género (en el caso español) o reproducir desigualdad o generar violencia contra la mujer (en el caso argentino).

De esta forma, la indefinición y la inconmensurabilidad de los estereotipos hacen realmente complejo valorar el grado de sexismo y la legalidad/ilegalidad de los manifiestos publicitarios. Una dificultad que viene dada en esencia por la ambigüedad terminológica.

Así, en términos de la comunicación comercial, el estereotipo es una herramienta insoslayable puesto que toda publicidad, por definición, es siempre o casi siempre estereotípica. Como apunta Velasco (2002: 380), la publicidad necesita de clichés para caracterizar, de forma clara y rápida, a los personajes. Sin embargo, en términos de las ciencias sociales y de las políticas públicas, el estereotipo se ha entendido por el legislador como un disvalor.

Se produce así un desencuentro generado por los juegos del lenguaje que se complica cuando hay que dilucidar cuándo estos clichés coadyuvan a generar violencia y cuando no, máxime si se tiene en cuenta que los estereotipos (publicitarios) pueden ser positivos o negativos (García, 2003: 72).

\subsection{La propuesta de los sesgos de género}

En un intento por proporcionar claves para la realización de noticias de salud sin sesgo de género, en el año 2004, desde la salud pública, Ruiz, Martín Llaguno, La Parra, Vives y Albadalejo trataron de precisar qué se entendía por este concepto. Así, estos autores consideran que, en general, el sesgo se produce "siempre y cuando uno de los 2 sexos reciba un tratamiento informativo perjudicial, en especial, cuando se compara con el recibido por el otro sexo" (Ruiz et al., 2004: 67). Para hacer operativo el concepto, se construyeron indicadores que permitieran captar estos aspectos perjudiciales para hombres y mujeres en los mensajes a partir de tres criterios: visibilidad, paridad y empoderamiento.

Los investigadores concretaban estos términos en una sencilla operacionalización a partir de la cuantificación de situaciones en las que a) aparecieran hombres y mujeres como protagonistas (visibilidad); b) aparecieran hombre o mujeres haciendo, diciendo o padeciendo acciones (paridad) y c) se transmitieran mensajes que hicieran tomar o acatar decisiones a hombres o mujeres (empoderamiento). 
Nos parece que si la propuesta de Ruiz et al. (2004) hubiera sido tenida en cuenta por el legislador la valoración del sexismo en el discurso publicitario se habría facilitado y por eso nos planteamos valorar su utilidad en la observación de los manifiestos publicitarios.

\section{Objetivos}

El objetivo inicial de este trabajo es revisar anuncios españoles y argentinos, a la luz de las delimitaciones de la publicidad sexista que hacen las Leyes Integrales de Violencia de Género observando,

- El uso del cuerpo (femenino y masculino) y su vinculación con los productos publicitados;

- La presentación estereotípica de hombres y mujeres.

- La existencia o inexistencia de sesgos de género en los anuncios valorando la visibilidad, la paridad y el empoderamiento de ambos sexos.

\section{Método}

\subsection{Estrategias metodológicas}

Con la finalidad de cumplir nuestros objetivos hemos realizado un análisis de contenido de una muestra representativa de spots emitidos en un mismo periodo por las televisiones y cines españolas y argentinas.

Esta metodología ha sido escogida por ser utilizada en investigaciones que analizan los valores trasmitidos por la publicidad con la finalidad de comparar sus semejanzas y diferencias en distintas sociedades o países, destacando los estudios que analizan las relaciones de género y los estereotipos (Rausell et al., 2009: 204-205).

\subsection{Población y muestra}

Se ha delimitado el universo de estudio a los anuncios de ambos países presentados al festival de referencia para la creatividad, "El Sol, el Festival Iberoamericano de la Comunicación Publicitaria" en la edición del 2009, teniendo en cuenta la categoría "TV/Cine". El total de spots inscritos ha sido de 242 para el caso español y 104 para el argentino.

Para determinar nuestra muestra, nos hemos servido del programa EPIDAT 3.1. El tamaño poblacional ha sido extraído con la finalidad de estimar proporciones, para ello, se ha tenido en cuenta un nivel de confianza del $95 \%$ con un margen de error del $5 \%$, una proporción esperada del $50 \%, P=0,5$ y, un nivel de precisión del 10\%. Así, se han analizado 69 anuncios 
españoles y 50 argentinos. La selección de las piezas se ha realizado también con EPIDAT 3.1, a partir de dos muestreos probabilísticos aleatorios simples con probabilidades iguales, uno para Argentina y otro para España.

\subsection{Instrumentos de recogida de información}

Al fin de observar el uso del cuerpo, la presentación estereotípica de sexos y los potenciales sesgos de género, se ha elaborado un código con 54 variables compiladas en 4 categorías relevantes para la investigación: a) Características del anuncio; b) Características de los personajes principales; c) Características de los personajes secundarios y c) otros.

Se han preparado unas hojas de codificación específicas y un manual de instrucciones, en el que se explicó detalladamente la manera de catalogar cada variable. De esta forma se ha tratado desde el principio que los codificadores clasificaran los anuncios de la manera más homogénea y objetiva posible.

El conjunto de ítems incluidos en el protocolo de codificación procede en parte del utilizado por Martín-Llaguno, Quiles y López (2004) y García del Castillo, López-Sánchez, Quiles y García del Castillo-López (2009), para el estudio de la publicidad de alcohol y tabaco, y en parte del usado por Ruiz et al. (2004) para el estudio de los sesgos de género en las noticias de salud.

De los primeros estudios se ha extraído el elenco de roles desempeñados por el hombre y por la mujer codificados. Así, se han adaptado los estereotipos indicados por ambos estudios para comprobar la existencia o inexistencia de marcos de presentación tradicionales para ambos sexos. Del segundo, se ha utilizado la cuantificación del concepto sesgo de género a través de sus indicadores: visibilidad, paridad y empoderamiento.

\subsection{Procedimiento}

En primer lugar, se diseñaron los instrumentos para la recogida de la información. Pese a que éstos fueron creados ad hoc, como se ha señalado anteriormente, son el resultado de las adaptaciones de anteriores investigaciones.

En segundo lugar, tras la obtención de los anuncios que conforman el universo de estudio gracias a la colaboración de la Asociación Española de Agencias de Comunicación Publicitaria, se extrajo la muestra para la realización del análisis de contenido.

En tercer lugar, los codificadores efectuaron el registro. El análisis de los datos se realizó a través del programa informático SPSS 15. En el proceso de codificación trabajaron durante un mes dos personas, con un índice de Kappa entre ellos del 0,90. 
Finalmente, con el propósito de observar las diferencias y similitudes entre sexos en los spots, y entre los spots españoles y argentinos, se han utilizado tablas de contingencia y de respuesta múltiple. Éstas han sido empleadas de forma descriptiva, a través del recuento y de los porcentajes. Así mismo, se ha comprobado la precisión estadística de las asociaciones entre las variables mediante los tests de Chi-cuadrado de Pearson ${ }^{3}$.

\section{Resultados}

\subsection{Uso del cuerpo femenino y su relación con el producto en los spots}

Como se puede observar en la tabla 2, la utilización del cuerpo desvinculado del producto, en ambos países, es escasa. En España, y en caso del cuerpo femenino, no hay ningún spot en el que se vincule ni a personajes protagonistas ni secundarios. En el caso del cuerpo masculino sí se produce esta situación en dos anuncios para los personajes protagonistas (a través de un spot de pizzas de la marca Carrefour elaborado por la agencia Publicis Comunicación España y de un anuncio de Vodafone realizado por la agencia Tapsa Madrid) y uno para los secundarios (un anuncio de la agencia Bap \& Conde para los supermercados Gadis).

Con relación a Argentina, hay más situaciones en los que los spots vinculan el cuerpo de los protagonistas (femeninos y masculinos) y de personajes secundarios a productos con los que no están relacionados. Los personajes protagonistas aparecen desvinculados del producto en dos ocasiones, un spot en el caso de los hombres (a través de la agencia Ponce Buenos Aires para el desodorante de la marca Axe) y uno para las mujeres (mediante la agencia Ogilvy \& Mather Argentina para la bebida Sprite). En el caso de los personajes secundarios, esta situación se produce en dos ocasiones para las mujeres (un anuncio de la agencia Ponce Buenos Aires para el gel de ducha Axe, que obtuvo el Sol de oro, y un spot de Craverolanis para una exposición de Roy Lichtenstein en el Museo de Arte Latinoamericano Malba), en el caso masculino, se muestra al hombre desvinculado del producto a través del mismo anuncio de la agencia Craverolanis para Malba.

Sin embargo, son tan pocas las situaciones que las diferencias entre países no son estadísticamente significativas.

\footnotetext{
${ }^{3}$ Para la realización del análisis estadístico, se considera el criterio de significación $p<0,05$, con un nivel de confianza del 95\%. Es decir, cuando el valor Chi-cuadrado es menor que 0,05, se considera que se produce una relación estadísticamente significativa entre las variables consideradas.
} 
Tabla 2: Utilización del cuerpo desvinculado del producto en los anuncios españoles y argentinos

\begin{tabular}{|c|c|c|c|c|c|}
\hline Personajes $^{a}$ & $\begin{array}{l}\text { Cuerpo desvinculado } \\
\text { del producto } \\
\text { promocionado }\end{array}$ & Anuncios & España & Argentina & TOTAL \\
\hline \multirow[t]{4}{*}{ PROTAGONISTAS } & \multirow[t]{2}{*}{ Hombres } & Recuento & 2 & 1 & 3 \\
\hline & & \% país & 66,7 & 20 & \\
\hline & \multirow[t]{2}{*}{ Mujeres } & Recuento & 0 & 1 & 1 \\
\hline & & \% país & 0 & 20 & \\
\hline \multirow[t]{4}{*}{ SECUNDARIOS } & \multirow[t]{2}{*}{ Hombres } & Recuento & 1 & 1 & 2 \\
\hline & & \% país & 33,3 & 20 & \\
\hline & \multirow[t]{2}{*}{ Mujeres } & Recuento & 0 & 2 & 2 \\
\hline & & \% país & 0 & 40 & \\
\hline
\end{tabular}

Los porcentajes y los totales se basan en las respuestas.

a. Agrupación de dicotomías. Tabulado el valor 1 .

Sólo en 31 de los 119 spots analizados (16 españoles y 15 argentinos), es decir, sólo en el $26 \%$ de los anuncios, se utilizan personajes desnudos o semidesnudos. En España, el porcentaje de cuerpos femeninos que se presentan no vestidos totalmente es mayor que el de cuerpos masculinos ( $56 \%$ frente a $44 \%$ ), mientras que en Argentina, la proporción es la inversa ( $60 \%$ de cuerpos masculinos, frente a $40 \%$ de femeninos). Sin embargo, tampoco las diferencias entre países son estadísticamente significativas.

\subsection{Marco de presentación de las mujeres y los hombres}

Hay más spots que ubican a los personajes en la esfera pública que en la privada y, en la mayoría de los casos, ambas esferas no parecen relacionadas. Hecha esta generalización, los anuncios sitúan preferentemente a los hombres, más que a las mujeres, en el ámbito público ( $76,5 \%$ de spots frente a $54,6 \%)\left(X^{2}=32,23 ; p=0,000\right)$ y a las mujeres más que a los hombres en el ámbito doméstico $(28,6 \%$ frente al $5 \%)\left(X^{2}=6,64 ; p=0,010\right)$, sin diferencias estadísticamente significativas por país.

A su vez, además de que en los spots de los festivales se presenta con más frecuenta a varones que a mujeres en el espacio laboral, las tareas profesionales desarrolladas por los hombres son típicamente masculinas, mientras que las profesiones desarrolladas por las mujeres son preferentemente neutras, siendo poco visibles en general las tareas típicamente femeninas y de cuidados $(p<0,05)$ (sin diferencias por país).

Por otra parte, como se puede observar en la tabla 4, el rol más frecuente que se ha utilizado para presentar a las mujeres en la publicidad, tanto en España como en Argentina ha sido el de trabajadoras de la esfera pública $(21,3 \%)$. La ubicación de los personajes femeninos como usuarias de productos, segundo perfil de presentación global $(15,3 \%)$ es el 
único caso en el que se aprecian diferencias estadísticamente significativas por país $\left(X^{2}=12,99 ; p=0,000\right)$, de forma que en España es mucho más usual perfilar a las féminas en este rol de consumidoras (21,6\%) que en Argentina (3,8\%). La presentación de la mujer como objeto de deseo sexual es el tercer perfil de presentación femenina en ambos países $(14,7 \%)$. Finalmente llama la atención que el papel de madre, que aparece en el $12,7 \%$ de las ocasiones en conjunto, es inferior al de padre, presente en el $19 \%$ de las piezas presentadas en el festival.

Tabla 3: Roles femeninos en la publicidad española y argentina

\begin{tabular}{|c|c|c|c|c|}
\hline 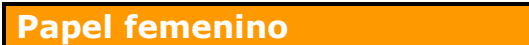 & Anuncios & España & Argentina & TOTAL \\
\hline \multirow{3}{*}{ Objeto sexual } & Recuento & 12 & 10 & 22 \\
\hline & \% país & 12,4 & 18,9 & \\
\hline & $\%$ total & 8 & 6,7 & 14,7 \\
\hline \multirow{3}{*}{ Supermujer } & Recuento & 10 & 5 & 15 \\
\hline & \% país & 10,3 & 9,4 & \\
\hline & $\%$ total & 6,7 & 3,3 & 10 \\
\hline \multirow[t]{3}{*}{ Ama de casa } & Recuento & 4 & 5 & 9 \\
\hline & \% país & 4,1 & 9,4 & \\
\hline & $\%$ total & 2,7 & 3,3 & 6 \\
\hline \multirow[t]{3}{*}{ Usuaria } & Recuento & 21 & 2 & 23 \\
\hline & \% país & 21,6 & 3,8 & \\
\hline & $\%$ total & 14 & 1,3 & 15,3 \\
\hline \multirow[t]{3}{*}{ Trabajadora de la esfera pública } & Recuento & 19 & 13 & 32 \\
\hline & \% país & 19,6 & 24,5 & \\
\hline & $\%$ total & 12,7 & 8,7 & 21,3 \\
\hline \multirow[t]{3}{*}{ Pasiva/sumisa } & Recuento & 7 & 3 & 10 \\
\hline & \% país & 7,2 & 5,7 & \\
\hline & \% total & 4,7 & 2 & 6,7 \\
\hline \multirow[t]{3}{*}{ Madre } & Recuento & 10 & 9 & 19 \\
\hline & \% país & 10,3 & 17 & \\
\hline & $\%$ total & 6,7 & 6 & 12,7 \\
\hline \multirow[t]{3}{*}{ Independiente } & Recuento & 2 & 0 & 2 \\
\hline & \% país & 2,1 & 0 & \\
\hline & $\%$ total & 1,3 & 0 & 1,3 \\
\hline \multirow[t]{3}{*}{\begin{tabular}{|l|} 
Dependiente \\
\end{tabular}} & Recuento & 5 & 5 & 10 \\
\hline & \% país & 5,2 & 9,4 & \\
\hline & $\%$ total & 3,3 & 3,3 & 6,7 \\
\hline \multirow[t]{3}{*}{ Seductora } & Recuento & 2 & 1 & 3 \\
\hline & \% país & 2,1 & 1,9 & \\
\hline & $\%$ total & 1,9 & 0,7 & 2 \\
\hline
\end{tabular}




\begin{tabular}{|l|l|l|l|l|}
\hline Preocupada aspecto físico y vestuario & Recuento & 5 & 0 & 5 \\
\cline { 2 - 6 } & $\%$ país & 5,2 & 0 & \\
\cline { 2 - 6 } & $\%$ total & 3,3 & 0 & 3,3 \\
\hline
\end{tabular}

Los porcentajes y los totales se basan en las respuestas.

a. Agrupación de dicotomías. Tabulado el valor 1.

\subsection{Sesgos de género}

\subsubsection{Visibilidad}

Como se deriva de los datos presentados en la tabla 5, la visibilidad masculina es superior a la femenina en ambos países $(p=0,000)$, especialmente en el caso argentino en el que no hemos encontrado ningún spot en el que no aparezcan personajes masculinos en el audio o en el video. Los personajes femeninos aparecen en el 76,5\% de los casos (sin diferencias estadísticamente significativas por país) frente a los personajes masculinos que aparecen en el $95,8 \%$ de los casos.

Tabla 4: Visibilidad de los personajes masculinos y femeninos para España y Argentina

\begin{tabular}{|l|l|l|l|l|}
\hline Visibilidad masculina & Anuncios & España & Argentina & TOTAL \\
\hline \multirow{2}{*}{$\begin{array}{l}\text { Aparecen personajes en imagen o } \\
\text { audio }\end{array}$} & Recuento & 64 & 50 & 114 \\
\cline { 2 - 5 } & $\%$ país & 92,8 & 100 & 95,8 \\
\hline \multirow{2}{*}{$\begin{array}{l}\text { No parecen personajes en imagen o } \\
\text { audio }\end{array}$} & Recuento & 5 & 0 & 5 \\
\cline { 2 - 5 } & $\%$ país & 7,2 & 0 & 4,2 \\
\hline Visibilidad femenina & Anuncios & España & Argentina & TOTAL \\
\hline \multirow{2}{*}{$\begin{array}{l}\text { Aparecen personajes en imagen o } \\
\text { audio }\end{array}$} & Recuento & 55 & 36 & 91 \\
\cline { 2 - 5 } & $\%$ país & 79,7 & 72 & 76,5 \\
\hline $\begin{array}{l}\text { No parecen personajes en imagen o } \\
\text { audio }\end{array}$ & Recuento & 14 & 14 & 28 \\
\cline { 2 - 5 } & $\%$ país & 20,3 & 28 & 23,5 \\
\hline
\end{tabular}

\subsubsection{Paridad}

Existen diferencias estadísticamente significativas a favor de los hombres en las proporciones en las que éstos dicen (39,2\% frente a $25,5 \%$ ) y a favor de las mujeres en las proporciones en las que éstas padecen (30,4\% frente al 19,6\%).

Aunque la diferencia entre la proporción entre las mujeres y los hombres que hacen es, en global, casi de un 3\% a favor de las primeras (44\% frente a 41,2\%) hay diferencias estadísticamente significativas en este aspecto entre los anuncios según el país. Así, hay un $17,4 \%$ de spots españoles analizados en los que los hombres no hacen, situación prácticamente inexistente en Argentina (4\%). 
Tabla 5: Paridad de los personajes masculinos y femeninos para España y Argentina

\begin{tabular}{|c|c|c|c|c|}
\hline Paridad masculina & Anuncios & España & Argentina & TOTAL \\
\hline \multirow[t]{3}{*}{ Dicen } & Recuento & 56 & 44 & 100 \\
\hline & \% país & 40,9 & 37,3 & \\
\hline & \% total & 22 & 17,3 & 39,2 \\
\hline \multirow[t]{3}{*}{ Hacen } & Recuento & 57 & 48 & 105 \\
\hline & \% país & 41,6 & 40,7 & \\
\hline & \% total & 22,4 & 18,8 & 41,2 \\
\hline \multirow[t]{3}{*}{ Padecen } & Recuento & 24 & 26 & 50 \\
\hline & \% país & 17,5 & 22,0 & \\
\hline & \% total & 9,4 & 10,2 & 19,6 \\
\hline Paridad femenina & Anuncios & España & Argentina & TOTAL \\
\hline \multirow[t]{3}{*}{ Dicen } & Recuento & 27 & 20 & 47 \\
\hline & \% país & 25,7 & 25,3 & \\
\hline & \% total & 14,7 & 10,9 & 25,5 \\
\hline \multirow[t]{3}{*}{ Hacen } & Recuento & 50 & 31 & 81 \\
\hline & \% país & 47,6 & 39,2 & \\
\hline & $\%$ total & 27,2 & 16,8 & 44 \\
\hline \multirow[t]{3}{*}{ Padecen } & Recuento & 28 & 28 & 56 \\
\hline & \% país & 26,7 & 35,4 & \\
\hline & $\%$ total & 15,2 & 15,2 & 30,4 \\
\hline
\end{tabular}

Los porcentajes y los totales se basan en las respuestas.

a. Agrupación de dicotomías. Tabulado el valor 1.

\subsubsection{Empoderamiento}

Con respecto a la toma de decisiones, en el conjunto de los spots analizados, hay un $37 \%$ en los que aparecen hombres activos frente a sólo un 15\% de mujeres en la misma situación, con lo que las diferencias en la capacidad de actuación por sexos son estadísticamente significativas $(p=0,000)$. En este sentido, el empoderamiento masculino es especialmente relevante en el caso de Argentina, donde en un $52 \%$ de spots se presenta a varones que toman decisiones frente al $26 \%$ de los anuncios españoles que lo hacen $\left(X^{2}=8,35 ; p=0,004\right)$. En el caso femenino no hay diferencias por países: en España sólo el 13\% y en Argentina el $18 \%$ de anuncios aparecen mujeres resolviendo cuestiones.

Con respecto al acatamiento de decisiones, en conjunto, también hay más spots en los que los hombres acatan decisiones (10\%) que en los que lo hacen las mujeres $(2,5 \%)$ $(p=0,000)$. En el caso femenino, no hay diferencias estadísticamente significativas por país, pero de nuevo, en el caso masculino la diferencia es estadísticamente significativa $\left(X^{2}=\right.$ 9,35; $p=0,002)$ : los anuncios argentinos presentan más varones acatando órdenes $(20 \%)$ que los anuncios españoles $(2,9 \%)$. 


\section{Discusión y conclusiones}

Los resultados obtenidos apuntan que, en virtud de lo estrictamente definido como sexista por las legislaciones, y al menos en lo que a España se refiere, parece haber una mejoría en algunos aspectos en la comunicación comercial con relación a la situación detectada por trabajos de antaño.

En efecto, en primer lugar, la técnica creativa de la utilización de los cuerpos femeninos para promocionar productos es inexistente en España y poco frecuente en Argentina, al menos en los spots para los festivales -a los que se les supone una dosis máxima de creatividad-. Sin embargo la objetualización del cuerpo masculino sí se produce en ambos países, debido en parte a que, como se ha expuesto, al restringir el concepto de publicidad sexista y eliminar a los varones como posibles sujetos de este tipo de publicidad, la normas legales no permiten denunciarla. Por otra parte, en España (no en Argentina), pese a la creciente sensibilidad que debería haber generado la entrada en vigor de la nueva normativa, la tendencia a presentar a la mujer desnuda sigue siendo mayor que la tendencia a presentar a los varones sin ropa (García, 2003: 192-193).

En segundo lugar y al margen de las cuestiones referidas a los asertos operacionalizables de las leyes integrales, lo cierto es que la entrada en vigor de las normativas parece haber propiciado también algunos otros cambios sutiles. Así, a partir de nuestros datos y en comparación con otros trabajos (De Pablos, 2005: 31-33) en este último lustro se ha producido una traslación -no relativa, sino casi absoluta- de la mujer del ámbito privado al público. Cuando las féminas han aparecido en este espacio social no lo han hecho como una prolongación de su papel como madre o ama de casa (2005: 31), sino como una iniciación en su papel de consumidoras o trabajadoras, incidiendo en el rol nuclear de la profesional. Aún así, la mujer trabajadora sigue apareciendo en menor medida que el hombre profesional (García, 2003: 207).

La inmersión del varón en la esfera privada por el contrario, no ha tenido la misma velocidad. Si bien es cierto que, como ya se viene apuntando desde hace unos años, la publicidad empieza a mostrar hombres en ella (De Pablos, 2005: 31-33), el problema es que, en la comunicación comercial, como en las leyes, el ámbito privado parece estarse infravalorado e "invisibilizando" en detrimento del público. La proporción de anuncios que se sitúan en la esfera privada tiene a ser cada vez menor. Aunque en ella, el varón sigue ostentando preferentemente el papel de padre (García, 2003: 207) -incluso por encima del de las madres- coincidimos con Del Moral (2000: 216) en que esta actividad se realiza de forma esporádica y no como algo habitual.

No obstante, tal y como se había adelantado, resulta realmente complejo valorar el grado de sexismo de los manifiestos publicitarios a través de las definiciones de publicidad ilícita realizadas tanto por la Ley Integral de Violencia de Género argentina como por la Ley General de Publicidad española, dada la inconcrección y la inconmensurabilidad de los 
conceptos "comportamientos estereotipos" y "patrones estereotipados" que coadyuvan a generar la violencia de género o reproducen desigualdad ¿Cuándo es sexista presentar en marcos distintos a varones y a mujeres en los anuncios? ¿Hasta qué punto esta presentación diferencial constituye una violencia simbólica o contribuye a generar el maltrato?

El concepto de sesgo se ha mostrado útil para valorar el trato prestado a hombres y mujeres en los anuncios. Así, a la luz de nuestro análisis se puede afirmar que, pese a las leyes integrales para prevenir la violencia machista, la publicidad española y argentina adolecen todavía de ciertos sesgos y se resisten, en algunos aspectos, a mostrar una representación equilibrada de ambos sexos.

De esta forma, incluso en los anuncios presentados a concursos de creatividad, la visibilidad global de los varones es considerablemente superior a la de las mujeres en la línea de los resultados obtenidos por Berganza y del Hoyo (2006: 165-166) y en contra de aquellos estudios que afirman que la mujer es una importante protagonista de la comunicación comercial (García, 2003: 171-172), ya que su cuerpo es utilizado para vender una gran cantidad de productos y llamar la atención (Del Moral, 2000: 214).

Tampoco los manifiestos publicitarios son paritarios puesto que los hombres no sólo dicen con mayor frecuencia que las mujeres -tal y como apuntaban las autoras anteriores (Berganza y del Hoyo, 2006: 169)-, sino que también tienden a padecer menos acciones.

Finalmente, y en lo que al empoderamiento se refiere, en ambos países los anuncios que muestran a hombres tanto tomando como acatando decisiones son más que los que muestran en la misma situación a las mujeres. En este caso no habría un sesgo de pasividad en detrimento de las féminas, pero sí lo habría de invisibilidad. No coincidimos con Del Moral (2000: 216) en que en la publicidad actual se muestre cada vez más a una mujer que prefiere decidir por sí misma, tanto en su vida laboral como personal; al menos no tanto como los hombres.

Cabe mencionar como principal limitación de este estudio el hecho de que los anuncios analizados forman parte de la base de datos de la edición de 2009 de "El Sol, el Festival Iberoamericano de la Comunicación Publicitaria" lo que implica que ninguno de ellos ha sido reclamado ni denunciado por vulnerar la legislación vigente tanto en España como en Argentina, es decir, que todos ellos son spots que respetan la legalidad (para obtener más información véase http://www.elsolfestival.com/reglamentoComun.asp?ord=1). Asimismo estos anuncios son un exponente de la mejor creatividad producida en ambos países, de forma que, si para este trabajo se hubieran seleccionado una muestra de spots difundidos por las televisiones al azar, los resultados podrían haber variado.

Queremos finalizar apuntando que se abre con esta propuesta toda una línea de intervención y de análisis. Entendemos que con las nuevas normativas el legislador ha querido enfatizar el importante papel de la publicidad en la construcción de las identidades de género en el 
imaginario colectivo. Pero desde la investigación y la expertise en la comunicación comercial es preciso hacer llegar a los poderes públicos estudios que comprueben la funcionalidad/disfuncionalidad de las normas promulgadas.

Coincidimos en que hay que plantear medidas que permitan erradicar sesgos e ir ganando en igualdad real. Pero entendemos que estas normas deben ser claramente aplicables y huir de la ambigüedad. Intuimos que el uso de los términos propuestos en las leyes (esterotipos, patrones estereotipados que coayuden a generar violencia) no permite valorar el estado de la comunicación comercial con enfoque de género. No obstante, desde ya nos planteamos volver a evaluar, dentro de unos años, los discursos publicitarios sometidos a las nuevas normativas para ver si se han modificado sustancialmente y para sopesar si se ha producido una conexión efectiva entre sus cambios y los cambios en la incidencia de la violencia real. 


\section{REFERENCIAS BIBLIOGRÁFICAS}

Berganza, Ma Rosa y Del Hoyo, Mercedes (2006): "La mujer y el hombre en la publicidad televisiva: imágenes y estereotipos", en Zer, no 21, pp. 161-175.

Blanco, Elena (2009): "Violencia de género y publicidad sexista en los medios", en Revista Latinoamericana de Comunicación Chasqui, no 105, en http://www.comunica.org/chasqui/content/view/17/1/ (consultado: 24/05/2011).

De PABlos, José Manuel (dir) (2005): "Los nuevos modelos de mujer y de hombre de la publicidad televisiva actual", en Consejo Audiovisual de Cataluña, Barcelona, en http://www.cac.cat/web/recerca/estudis/llistat.jsp?MjU\%3D\&MQ\%3D\%3D\& L3dIYi9yZWNIcmNhL2VzdHVkaXMvbGxpc3RhdENvbnRIbnQ\%3D (consultado: el 24/05/2011).

Del MORAL, Ma Esther (2000): "Los nuevos modelos de mujer y de hombre a través de la publicidad", en Comunicar, nº 14, pp. 208-217.

García Del Castillo, José A. et al. (2009): "Descripción y análisis de la publicidad de Alcohol en la revista Muy Interesante", en Revista Latina de Comunicación Social, no 64, pp. 461-468.

GARCÍA, Patricia (2003): "Estereotipos de género en publicidad televisiva". Tesis Doctoral. Málaga, Universidad de Málaga.

Lavine, Howard; Sweeney, Donna y Wagner, Stephen H. (1999): "Depicting Women as Sex Objects in Television Advertising: Effects on Body Dissatisfaction", en Personality and Social Psychology Bulletin, vol, 25, no 8, pp. 1049-1058.

LeY ORgánicA 1/2004, de 28 de diciembre, de Medidas de Protección Integral contra la Violencia de Género. Boletín Oficial del Estado, 29 de diciembre de 2004, número 313.

LEY 34/1988, de 11 noviembre, General de Publicidad. Boletín Oficial del Estado, 15 de noviembre de 1988, número 247.

LEY 26.485, de protección integral para prevenir, sancionar y erradicar la violencia contra las mujeres en los ámbitos en que desarrollen sus relaciones interpersonales, Boletín Oficial de la República Argentina, 14 de abril de 2009, número 31632.

LOSCERTALES, Felicidad y NúÑEZ, Trinidad (2009): "La imagen de las mujeres en la era de la comunicación", en Revista Científica de Información y Comunicación, no 6, pp. 427-462. 
Martín-Llaguno, Marta; Quiles, Ma Carmen y LóPEZ, Carmen (2004): "Los sistemas de autorregulación como mecanismos de control de la publicidad de tabaco: evaluación mediante análisis empírico", en Gaceta Sanitaria, vol. 18, no 5, pp. 366-373.

RAuSELL, Claudia et al. (2009): "Los valores sociales en los spots de automóviles emitidos en España en 2006", en Anàlisi, no 38, pp. 199-217.

Rodríguez, Carmen; MATUd, Ma Pilar y EsPinOSA, Inmaculada (2008): "Roles de género en la prensa diaria nacional", en Estudios Sobre el Mensaje Periodístico, no 14, pp. 575-580.

RODRÍGUEZ, Rosa (2008): "Del crimen pasional a la violencia de género: evolución y su tratamiento periodístico", en Ámbitos, no 17, pp. 171-188.

Ruiz, María Teresa et al. (2004): "El enfoque de género en las noticias de salud", en Gaceta Sanitaria, 18 (Extra 2), pp. 65-74.

SÁnCHEZ, Gabriel (2008): "Violencia Machista y medios de comunicación. El tratamiento de los delitos relacionados con el maltrato a mujeres", en Comunicación y hombre, no 4, pp. 155-167.

StRASBURGer, Víctor C. (2004): "Children, adolescents, and the media", en Current Problems in Pediatric and Adolescent Health Care, vol. 34, no 2, pp. 54-113.

VELASCO, María Sol (2002). "Publicidad y género: propuesta, diseño y aplicación de un modelo de análisis de las metáforas de género en la publicidad impresa en lengua inglesa". Tesis doctoral. Valladolid, Universidad de Valladolid.

VIVES, Carmen (2004): "La violencia contra las mujeres en el espacio discursivo público". Tesis Doctoral. Alicante, Universidad de Alicante.

Vives-Cases, Carmen; Ortiz-Barreda, Gaby y Gil-GonzÁlez, Diana "Mapping violence aganist women laws in the world: an overview of state commitments", en Journal of Epidemiology and Community Health, vol. 64, n० 6, pp. 474-475.

[Recibido: 31 de mayo de 2011. Aceptado: 12 de junio de 2012]. 